\title{
CLINICAL STUDY OF BENIGN BREAST DISEASES
}

\author{
K. Shantha Kumar'1, P. Anbalagan², V. Udhayasankar ${ }^{3}$
}

${ }^{1}$ Associate Professor, Department of General Surgery, Government Vellore Medical College and Hospital, Vellore, Tamilnadu. ${ }_{2}^{2}$ Assistant Professor, Department of General Surgery, Government Vellore Medical College and Hospital, Vellore, Tamilnadu. 3Junior Resident, Department of General Surgery, Government Vellore Medical College, Vellore, Tamilnadu.

ABSTRACT
BACKGROUND
Vast majority of lesions in breast are benign. More concern is given to malignancy of breast. It is the most common malignancy in
female. Because the benign breast lesions are not associated with subsequent breast cancer, unnecessary surgical procedures can be
avoided. Fine needle aspiration cytology plays an important role in preoperative diagnosis of breast lumps. It influences the
modalities of treatment and avoids many unnecessary surgeries. Here, we have tried to establish the incidence of benign breast
lesions and accuracy of FNAC in diagnosing benign breast lesions.

\section{MATERIALS AND METHODS}

This study has been undertaken in cases in Department of General Surgery, Govt. Medical College in patients with breast lump from 1.5.2015 to 1.6.2016 in a study population of 128 with all age groups.

\section{RESULTS}

The most common age of incidence of benign breast lesions were found to be 15 - 55 years except for 4 cases. Youngest age of the patient is 14 and eldest was 60 years. Sensitivity and specificity of FNAC for diagnosing fibroadenoma is $98.8 \%$ and $75 \%$, for fibrocystic disease is $75 \%$ and $99 \%$, for phyllodes tumour is $80 \%$ and $100 \%$, for chronic mastitis is $80 \%$ and $100 \%$, and for fibroadenosis is $22 \%$ and $80 \%$.

\section{CONCLUSION}

Our study proves that benign breast disorders are common in reproductive age group. Fibroadenoma is the most common benign breast lesion. Right upper and outer quadrant is the commonest position of lump in the breast. FNAC is the most useful diagnostic modality with high specificity and positive predictive value.

\section{KEYWORDS}

Benign Breast Lesion, Incidence, FNAC, Excision Biopsy.

HOW TO CITE THIS ARTICLE: Kumar KS, Anbalagan P, Udhayasankar V. Clinical study of benign breast diseases. J. Evolution Med. Dent. Sci. 2017;6(2):132-135, DOI: 10.14260/Jemds/2017/32

\section{BACKGROUND}

Benign breast disorder and diseases encompasses a wide range of pathologic entities. Benign breast disorders correlate to architectural anatomy involved and changes occurring in breast at various ages.

\section{Physiological Changes in Breast} Changes during Menstrual Cycle

Retention of fluid during luteal phase, breast engorgement and pain.

\section{Changes during Pregnancy}

There is diminution of fibrous stroma and formation of new acini and lobules known as 'Adenosis of Pregnancy.'

Financial or Other, Competing Interest: None.

Submission 02-11-2016, Peer Review 15-11-2016,

Acceptance 18-11-2016, Published 05-01-2017.

Corresponding Author:

Dr. K. Shantha Kumar,

Associate Professor

Department of General Surgery,

Government Vellore Medical College \& Hospital

Chengalpattu-603001, Kanchipuram District,

Tamilnadu.

E-mail:drkskumarmmc@gmail.com

DOI: $10.14260 /$ jemds $/ 2017 / 32$

\section{Changes during Lactation}

The alveoli are distended with milk, the cells become cuboidal, there is resultant diminution of intralobular space.

\section{Changes at Menopause}

Involution starts occurring at 35 years of age with regression of glandular tissue, its replacement by fat and fibrosis. This fatty infiltration produces the low density appearance of parenchyma in mammography and reason for benign breast disorder that occur in this age group.

\section{Aberration of Normal Development and Induration}

The basic principles underlying the classification of benign breast disorders are,

1. Benign breast disorders and diseases are related to the normal process of reproductive life to involution.

2. It is a spectrum of benign breast conditions ranging from normal to disorder to disease.

3. ANDI encompasses all aspects of breast including pathogenesis and degree of abnormality. 


\begin{tabular}{|c|c|c|c|}
\hline & Normal & Disorder & Disease \\
\hline \multirow[t]{4}{*}{$\begin{array}{l}\text { Early Reproductive Years } \\
\text { (age } 15-25 \text { ) }\end{array}$} & Lobular Development & Fibroadenoma & $\begin{array}{c}\text { Giant } \\
\text { Fibroadenoma }\end{array}$ \\
\hline & Stromal Development & $\begin{array}{l}\text { Adolescent } \\
\text { Hypertrophy }\end{array}$ & Gigantomastia \\
\hline & Nipple Eversion & Nipple Inversion & Subareolar Abscess \\
\hline & & & Mammary Duct Fistula \\
\hline \multirow[t]{3}{*}{$\begin{array}{l}\text { Later Reproductive Years Age } \\
25-40 \\
\end{array}$} & Cyclical Changes of Menstruation & Cyclical Mastalgia & Incapacitating Mastalgia \\
\hline & Nodularity & & \\
\hline & $\begin{array}{l}\text { Epithelial Hyperplasia Of } \\
\text { Pregnancy }\end{array}$ & $\begin{array}{l}\text { Bloody Nipple } \\
\text { Discharge }\end{array}$ & \\
\hline \multirow[t]{6}{*}{ Involution (age 35 - 55) } & Lobular Involution & Macrocysts & \\
\hline & & Sclerosing Lesions & \\
\hline & Duct Involution & & \\
\hline & - $\quad$ Dilatation & Duct Ectasia & Periductal Mastitis \\
\hline & Sclerosis & Nipple Retraction & \\
\hline & Epithelial Turnover & Epithelial Hyperplasia & $\begin{array}{c}\text { Epithelial Hyperplasia with } \\
\text { Atypia }\end{array}$ \\
\hline \multicolumn{4}{|c|}{ Table 1. ANDI Classification of Benign Breast Diseases } \\
\hline
\end{tabular}

\section{Objectives}

- To assess the usefulness of FNAC in diagnosing benign breast lesions.

- To assess the validity of image unguided FNAC technique.

- To assess the sensitivity and specificity of FNAC over excision biopsy.

- To study the age group commonly affected.

- To study the various clinical presentation of benign breast diseases.

\section{MATERIALS AND METHODS}

Duration of Study: 1 year

Population Studied: 128

Study Group: All Patients with Breast Lumps

Study Setting: Govt. Medical College.

\section{Materials to be used}

FNAC.

Excision biopsy.

\section{Inclusion Criteria for FNAC}

Age between 10 to 60 years.

Palpable breast lumps of variable duration with clinically benign nature.

\section{Exclusion Criteria for FNAC}

Patients not willing.

Clinically skin infiltrating malignancy.

\section{Inclusion Criteria for Excision Biopsy}

FNAC proved fibroadenoma and size more than $2 \mathrm{~cm}$

Fibrocystic disease which:

- Did not resolve after 2 aspirations.

- When aspirate was haemorrhagic.

- If it was a complex cyst.

\section{RESULTS}

All patients belong to age group 15 - 55 years except for four cases. FNAC was done in all 128 cases.

Comparative Results of FNAC with that of HPE reports.

\begin{tabular}{|c|c|c|}
\hline Disease & FNAC & HPE \\
\hline Fibroadenoma & 92 & 81 \\
\hline Fibroadenosis & 2 & 4 \\
\hline Fibrocystic disease & 19 & 24 \\
\hline Chronic mastitis & 4 & 5 \\
\hline Phyllodes tumour & 4 & 5 \\
\hline Galactocele & 2 & 2 \\
\hline TB Mastitis & 1 & 0 \\
\hline Gynaecomastia & 3 & 3 \\
\hline Ductal papilloma & 1 & 2 \\
\hline Table2. Patients Distribution by FNAC and HPE \\
\hline
\end{tabular}

\begin{tabular}{|c|c|c|c|c|}
\hline Disease & Sensitivity & Specificity & PPV & NPV \\
\hline Fibroadenoma & 98 & 75 & 87 & 97.3 \\
\hline Fibroadenosis & 25 & 99.2 & 50 & 99.7 \\
\hline $\begin{array}{c}\text { Fibrocystic } \\
\text { disease }\end{array}$ & 75 & 99 & 94.7 & 94.5 \\
\hline $\begin{array}{c}\text { Chronic } \\
\text { mastitis }\end{array}$ & 80 & 100 & 100 & 99.2 \\
\hline $\begin{array}{c}\text { Phyllodes } \\
\text { tumour }\end{array}$ & 80 & 100 & 100 & 99.2 \\
\hline \multicolumn{2}{|c|}{ Table3. FNAC in Diagnosing Benign Breast Lumps } \\
\hline
\end{tabular}

\section{Age Incidence}

Our study was done in 128 cases with age incidence common between 15 - 45 years except for 4 cases.

Youngest age was 14 and eldest was 60 years.

Fibroadenoma was commonly in 25 - 40 years of age (58/128).

Patients with fibrocystic disease were mostly seen in 25 40 years ( 14 out of 24 cases).

Patients with chronic mastitis belong to 25 - 40 years ( 3 out of 5 cases).

All 4 cases of adenosis belong to 25 - 40 yrs.

TB mastitis reported in age group 40 - 55 years.

Phyllodes tumour reported in $25-40$ years ( 2 out of 5 cases). 


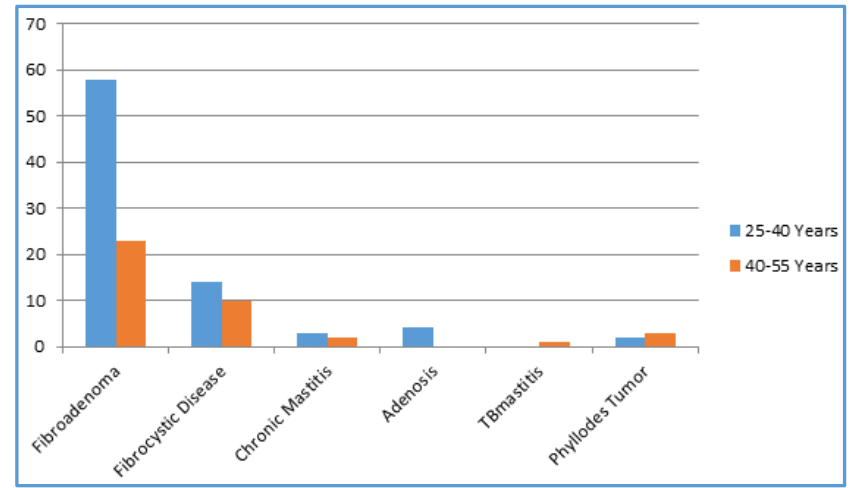

\section{DISCUSSION}

A lump in the breast is a common complaint presenting in the Surgical Outpatient Department of all major hospitals with anxiety regarding a possible malignancy being extremely common. Hence, a quick diagnosis of a lump in the breast is essential.

In our study, the age ranged from fifteen years to forty years with an exception of 4 cases. The maximum was found in the 25 - 45 years' age group followed by 51 patients in the 15 - 25 years' age groups. Benign breast disease lesions were seen in patients of all age groups; they were more commonly seen in younger age groups. In a similar study done by Hussain on 50 patients, the age distribution was between 15 and 65 years and the maximum patients were seen in the thirty one to forty years' age group (30\%).[1] Similar studies were done by Homesh et al, and Tiwari and Ariga et al showed similar age patients.[2] [3]

In our study the right breast was involved in 70 patients, while the left breast was involved in 53 patients. Bilateral involvement was seen in five patients. In their series, Hussain et al showed left breast involvement in 27 patients (54\%), while in the other 23 the right breast was involved. No surgical importance can be attached to this observation, since patient's selection was in no way dictated by involvement of any particular breast.

The upper and outer quadrant was the commonest site of the lump in our patients (55 patients), while the upper inner quadrant was involved in 37, the lower and outer in 15 and the lower and inner quadrant in 9. Hussain, in his series had 29 patients (58\%) with the lump in the upper and outer quadrant. Both studies showed the upper and outer quadrant to be the dominant quadrant to have a palpable lump.

Benign breast disease are the commonest breast disease affecting women, more so in the age group of 25 to 40 years. In our study, fibroadenoma being the commonest breast lesion affecting the age group 25 to 40 years.

Fibroadenosis and chronic mastitis affecting the age group of 25 to 40 years. Patients present with main complaints of lump in the breast.

Pain was present as the additional complaint in patients with fibrocystic changes and mastitis.

Nipple discharge was present in a single case of duct papilloma and axillary node involvement, which was reactive in a case of phylloides tumour.

Cases of ductal papilloma and case of ductal carcinoma were missed in FNAC and diagnosed only by excision biopsy. But the ultimate diagnostic procedure in doubtful cases is always histopathological report.
Fine needle aspiration cytology has not only approved to be invaluable in the distinction of malignant from benign breast disease, but has also replaced the era of positive negative and suspicious cytological diagnosis with an ever enlarging potential of accurate morphological typing of various breast lesions including benign lesion.

Considering patient's comfort, lack of requirement of Anaesthesia, rapid analysis and reporting and absence of false positive results makes FNAC an ideal initial diagnostic modality in breast lumps. Continuous with most developed aspiration biopsy techniques are Sweden, Slovenia, the USA and India. At Karolinska Hospital (Stockholm, Sweden), FNACs average of 11,000 annually and at the Institute of Oncology Ljubljana, Slovenia 10,000. In the USA, the highest number is encountered at M. D. Anderson at Houston, Texas with 7,000 aspirates every year. At All India Institute of Medical Sciences (AIIMS), the annual volume of cytology specimens is more than 15,000 with FNACs comparing roughly half of the aspirations.

Our present study was conducted on 128 female patients with a palpable breast lump, each of whom underwent a fine needle aspiration cytology of the lump followed by excisional surgery either in the form of lumpectomy or a definitive surgery surgical procedure depending on the diagnosis at aspiration cytology. The aspiration cytology findings were then matched with the final histology report to see as to how accurate FNAC was as compared to open biopsy, i.e. to assess the cytohistological correlation. ${ }^{[4]}$

The procedure of FNAC was performed by trained personnel in the Pathology Department following a uniform protocol. All pathology specimen underwent a histopathological study, the final report was compared with that of FNAC and the correlation was sought. The results obtained were tabulated and conclusions drawn based on statistical tests. Though many aspects relating to the patients profile were tabulated and compared with those in other similar studies, the most important aspects of this study was to draw conclusion regarding the cytohistopathological correlation in these patients.

Image guidance during FNAC is another important aspect of various studies. Increased accuracy is the obvious advantage especially in the smaller, deeper or impalpable lesions and also in fibrocystic disease and fibroadenosis as the sensitivity of FNAC is low. However, since we included only palpable breast lumps in our study, no image guidance was required in any patients.

Positive predictive value, negative predictive value, specificity, sensitivity for FNAC in each of benign breast diseases is calculated.

- Fibroadenoma - Sensitivity 98.8\%, Specificity 75\%, Positive predictive value $94.5 \%$, Negative predictive value 95.5\%.

- Fibroadenosis - Sensitivity 25\%, Specificity 99.2\%, Positive predictive value $50 \%$, Negative predictive value 97.7\%.

- Chronic mastitis - Sensitivity $80 \%$, Specificity $100 \%$, Positive predictive value $100 \%$, Negative predictive value 99.2\%.

- Phylloides tumour - Sensitivity $80 \%$, Specificity $100 \%$, Positive predictive value $100 \%$, Negative predictive value 99.2\%. 


\section{CONCLUSION}

The primary aim of our study is to determine diagnostic correlation between FNAC and HPE report of breast lump. For centuries conventional histology has remained the cornerstone of diagnostic pathology, often described as the final court of appeal in the presence of controversy.[1][2]

Our study proved that benign breast disorders are common in reproductive age group.

Fibroadenoma is the commonest benign breast lesion.[3] FNAC is the most useful diagnostic modality with high specificity and positive predictive value. ${ }^{[4]}$ Excision biopsy is the investigation of choice in doubtful cases.

\section{REFERENCES}

1. Hussain MT. Comparison of FNAC with excision biopsy of breast lump. J Coll Physicians Surg Pak 2005;15(4):211-4.

2. Homesh NA, Issa MA, El-Sofiani HA. The diagnostic accuracy of FNAC versus core needle for palpable breast lump(s). Saudi Med J 2005;26(1):42-6.

3. Tiwari M. Role of fine needle aspiration cytology in diagnosis of breast lumps. Kathamandu University Medical Journal 2007;5(18):215-17.

4. Edmund, Barbara. Cytology-diagnostic principles and clinical correlates. $3^{\text {rd }}$ edn. Elsevier 2009. 